\title{
The Studise of Practices on Strengthening Village Ecological Landscape Conservation Planning
}

\author{
Yijie Zhang \& Ning Wang \&Xiaofei Ren \\ Urban and Rural Planning, Agricultural University of Hebei Province, Baoding, 071000, China
}

\begin{abstract}
This paper, from the angle of ecology landscape, analyzed and discussed in detail the ecology landscape planning in Wangnao village's development. What's more, it also made thinking and introspect during the practice. combining its ecology landscape, ecoturism landscape etc. as superior resources, for one thing, it can protect the ecology of natural environment, for another thing, it can protect historical and cultural civilization, in addition, it can promote harmonious development in Wangnao'socirty and economy.

KEYWORD: ecology landscape; ecoturism landscape; green eco-environment of village; harmonious development.
\end{abstract}

\section{BACKGROUND OF ECOLOGICAL LANDSCAPE STUDY}

Since the rapid development of rural economy in recent years, the environmental pollution and environmental degradation in some areas have brought incalculable loss to the development of many villages. The future sustainable development of these villages is becoming weak with the excessive consumption of the ecological environment, with the sustained extensive damage to the natural environment, and with continued wanton trampling of ecological landscape that cannot be repaired. It is undoubtedly worthless on the expense of environment in order to promote the economic growth.

The gap between the rural ecological environment causes are many, two of which are the most important one is the input, one is planning. As for the village planning, even more new rural construction "weakness." Village emphasis on the environment and landscape, a lack of planning, did not respect the local ecological environment in the first place, garbage misplacing, artificial rural landscape, ecological landscape has been a series of problems such as deterioration of brutal destruction of the ecological environment[1]. When this article to protect the ecological landscape planning, with emphasis on organic development and contribute to the rural ecological environment restoration, the purpose is to maintain the ecological balance of the region, protection of rural local culture, texture and context of protected areas, protection of the natural environment and sustainable development .

\section{THE IMPORTANCE OF ECOLOGICAL LANDSCAPE PLANNING PROTECTION}

(1) Harmony is the core of the ecological landscape structure and function of inner and external environment, the degree of physical contact and ecological relationships. Making people mix with nature, return to nature, close to nature, the nature into the city. The most important is reflected in the people and society.

(2) Diversity: biosphere unique ecological phenomenon is reflected in the landscapes, ecosystems, species, social, industrial and cultural diversity. Ecological landscape planning is not a single development model and type, but fully reflect the geographical nature, economy, culture, history feature personalized plan.

(3) Security: the climate, the terrain, the resource supply of the city, has a strong safety on the physical and psychological effects on health and the environment. For areas of human, animal, plant, microbial and other offers tranquil and peaceful environment.

(4) Sustainability: the urban ecosystem has a strong self-organizing self-regulatory function, resulting in a higher eco-efficiency and social utility, and meet the healthy, coordinated and sustainable development of the city. 
Wangnao village lies in the west of Taihang Mountain area, Shahe City of Hebei Province. To enhance the ecological quality of rural residents, ecological landscape conservation planning, we create a set of natural environment, human environment, artificial environment for the integration of ecological landscape conservation planning.

\subsection{Ecological Landscape Planning Principles on Wangnao village}

Ecological architecture is based on the local natural environment, the use of ecology, the basic principles of building science and technology of modern science and technology, so that it becomes an organic combination between architecture and the environment, while the people, architecture and the natural ecological environment formed in a healthy circulatory system[2].

\subsection{Ecological Planning of Wangnao village buildings}

We should construct Wangnao village with new technologies, new materials, and new technology, and make use of solar energy, bio gas, natural gas, wind energy and other new energy sources as much as possible. We should intensively develop new houses in the form of terrace or line[3]. We'd better make the building group flexible, and unify the main style of building color. The public buildings' main color is red, the houses' is yellow, with red stones as embellishment. Residential style should character Nao village, such as the roof which is in the form of the Wangnao stone floor, the building stones and other elements.

\subsection{The new ecological landscape planning}

\subsubsection{Public toilets}

Village planning two public toilets are flush toilets installed a smelly soft stop valve, usually soft valve is turned off, preventing the harmful gases and return indoor pests, and when there is water and dirt naturally closed after the adoption. People strengthen the management and maintenance of these toilets to ensure hygiene. The new eco-type reflects the concept of sustainable development, is a sign of the development of human civilization.

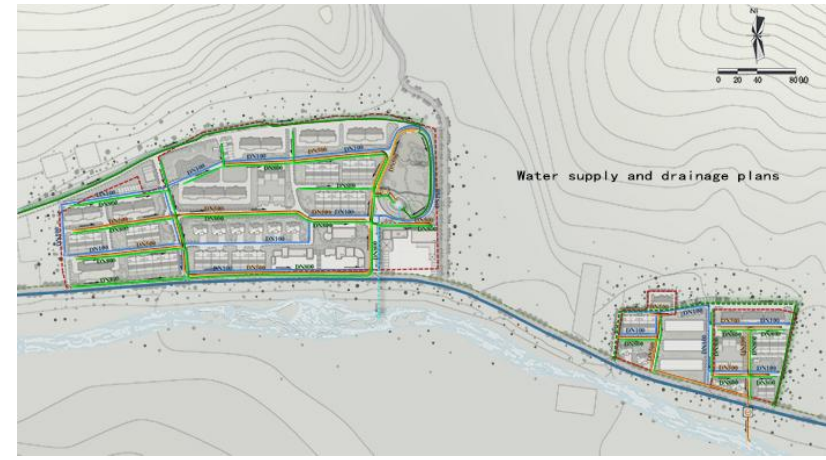

Figure 1 Water supply and drainage plans

\subsubsection{Water Supply Project Planning}

Water consumption, including water and public buildings residents living water. The village water supply pipeline laid along the main roads and secondary roads. Through the implementation of water supply project planning, you can avoid, mitigate or compensate for the negative ecological impacts of water supply projects in order to maintain the health and integrity of ecosystems.

\subsubsection{Sewage Project Planning}

Drainage system using triage system, namely rain and sewage system. Western sewage treatment facilities set up at the main entrance on the south side. Using biological filter sewage discharged into the river at south of the village flood to avoid flood damage. Eastern sewage treatment facilities arranged at the south side of the highway. The same way as Western sewage treatment, water treatment compliance village south into the spillway. By planning sewage ecological engineering, we can protect the environment and also reducing the cost of waste water treatment in order to achieve land resource utilization, and a win-win environment and life.

\subsubsection{Rainwater drainage project planning}

Rainwater collection pipe network uses slice, due to the potential emissions of the principle of proximity, will collect rainwater partition. Beside the road in the northern West setting cut Honggou, other road set underground rainwater pipes, cut the east side of the nullah Honggou connected with the landscape park, the water discharged in the Village Square pool. Interceptor ditches settings and anti torrents combined. Eastern rainwater through the open channel, culverts and drainage lines as the way into the village road in the south ditch. Ecological storm water drainage is to achieve a standard eco-city by planning in advance, system security, unified management of multilateral cooperation in order to accelerate the process of building ecological drainage, landscaping desire to better complete the urban environment. 


\subsection{Ecological landscape planning structure Wangnao village}

Wangnao Village has about six chunks mesa, and height difference between each of 1 to 1.5 meters, the low-lying west to east, combined with unique local topography, the waterfront green belt Wangnao Village, parks, street green and terrain blend together to form a "point, line, surface," a combination of green systems. "Point" - the landscape park, terraced park composition, is a major landscape nodes Wangnao Village, is an important place for recreation. "Line" - walking from the inner landscape corridors, street trees protective outer corridor components. "Face" - from the green room house, attached green, green and other types of roadside green components.

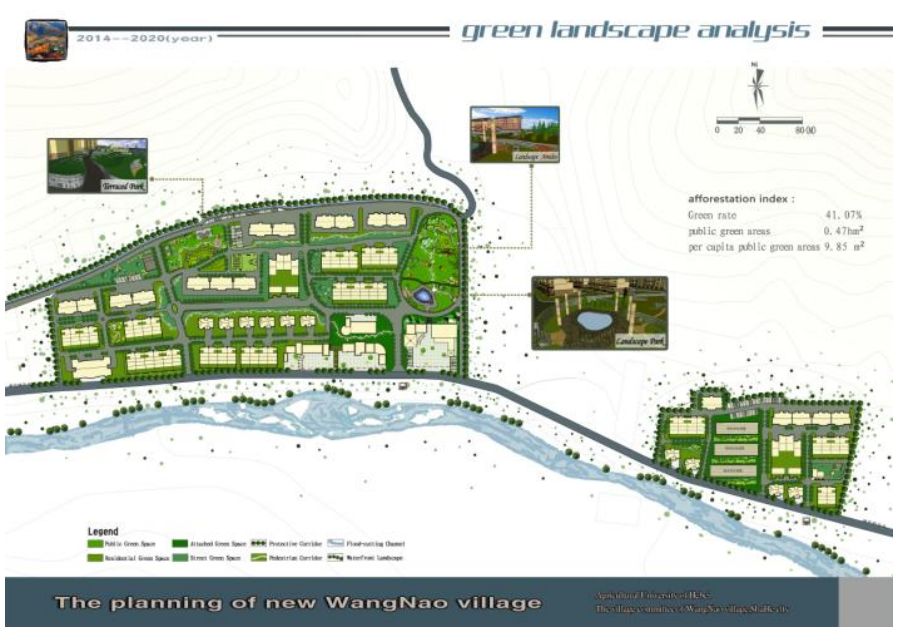

Figure 2 Green landscape analysls

\subsection{Tourism Ecological Landscape}

Eco tourism historic and cultural landscape, to have tourist attraction. Wangnao village is important that the local cultural folklore with the lowest carbon in series, the local population ages the most honest, simple lifestyle show, at the same time focusing on intensive land, with minimal interference to achieve optimal results."Implementation of industrial tourism region is formed inside the Eastern Wangnao village agricultural sightseeing garden, warm homes west green breeding base, warm home leisure experience area west of fruits and vegetables, forest landscape areas in order to achieve taste of rural life, improve industry links, and promote industrial ecology, better the low-carbon travel. The main public buildings have village, country inns, commercial buildings, kindergartens, square pool. Its commercial buildings combine Wangnao Village geographical features, take advantage of the terrain changes, improve village features, plan and set up a small business in the Village Area at the southeast corner of the West Village.

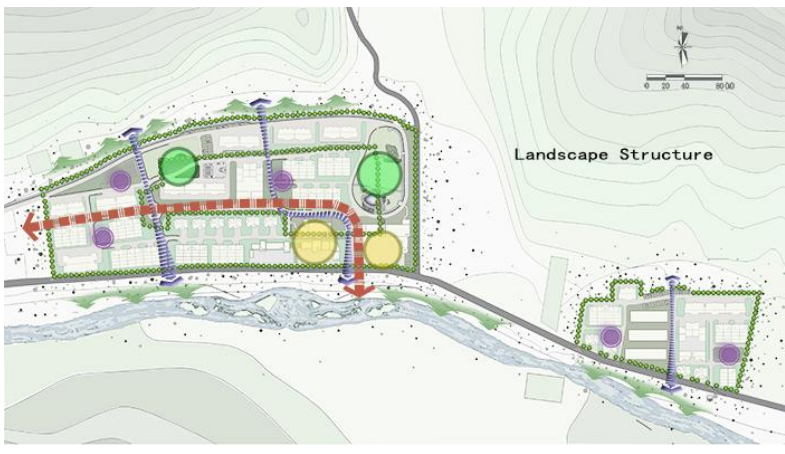

Figure 3 Landscape structure

\subsection{Village Green Ecological Planning}

\subsubsection{Village Green Plants}

With native trees, preference adaptable, cheap, easy to manage, environmentally friendly plants. Plant species of trees can be used like locust, elm, oak, pine, poplar, etc. Lilac flowers can be used, peony, chrysanthemum, rose, rose, rose, sunflower, jasmine, cactus, evening primrose, begonia, iris, orchid, lotus, and so on. Shrubs can be used Vitex, jujube, mountain elm, amorpha and mountain grapes, mountain bean vine and so on.

\subsubsection{Landscape ecology}

Landscaping principles to local conditions, make full use of natural resources, mining and inheritance villages original features only put it through siting, landscape construction, plants use to configure the whole process, in order to achieve localization, the original ecology, natural simplicity, because only so as to reflect the beauty of the original ecology, natural simplicity of beauty. Village Landscape ecology to respect nature, to respect the basic principles of nature, natural landscape features enhanced Village, preserving the natural environment of the village style, make artificial landscape in harmony with the natural landscape, human settlements inject vitality[4]. Planning to configure certain proportion of tall trees, supplemented by an appropriate number of shrubs, small trees and ground cover plants, thus creating rich layers of vegetation, the visual effect is good green landscape.

\section{SUMMARY}

China's rural economy is facing growing serious environmental crisis under the background of the rapid development. The rural planning subjects should adopt a pragmatic attitude, starting from the ecological effectiveness, re-pondering planning technology system and institutional environment, and conduct a targeted reform. The planning subjects should play their "leading" role in the coordination between man and nature. 
Ecological landscape planning and design not only can solve some problems of rural ecological landscape construction and focused on repairing ecological environment in the villages, but also can improve the rural environment and landscape features and continue the historical context of the villages. Still, it can provide strategic control to the villages' important ecological resources.

The ecological landscape planning and design of Wangnao Village is designed based on some factors, such as natural environment, cultural environment and artificial environment. It combines ecological and environmental protection, low carbon travel, culture and leisure functions as a whole, which could not only protect the natural environment, but also improve the village's social economic harmonious development.

\section{REFERENCES}

[1] Naveh Z,Lieberman A S. Landscape Ecology: Theory and Application. New York: Springe-Verlag, 1984.

[2] Roseland M. Dimensions of the future: An Ecocity overview, 1997.

[3] Yanitsky, The city and ecology. Moskow, Nanka, 1987.

[4] Yu K, Li D, Li N. The evolution of greenways in China. Landscape and Urban Planning, 2006, 76(1-4): 223-238. 